\title{
Research on the Dilemma of "Consumerism" in the Construction of Green Consumption System from a Micro Perspective
}

\author{
Rui Hao \\ Kunming University of Science and Technology \\ Kunming, China
}

\begin{abstract}
Consumerism" as a value concept of excessive consumption first appeared in Western capitalist society. In recent years, China's national production level and the consumption level of urban and rural residents have been continuously improved, but the concept of green consumption has not been popularized. In addition, the nationals have gradually deviated from the traditional concept of "harmony between human and nature", which has led to the appearance of "consumerism". The report of The 19th Session of National Congress put forward the requirements for the construction of ecological civilization, pointing out that the concept of green consumption as a precondition for consumers to make green consumption behaviors must get rid of the predicament of "consumerism". This paper has explored the guidance of core values, the promotion of innovative consumers and the strengthening of consumer will from the micro perspective of consumers, and has further explored how to construct a green consumption system.
\end{abstract}

Keywords-consumerism; green consumption; selfconstruction theory

\section{INTRODUCTION}

There is a big difference between the green consumption pattern and the traditional consumption pattern. The traditional consumption mode puts people and nature in a hostile position. It is based on the ethical basis of "people defeating nature" and pursues the uncontrolled increase of the quantity of consumption. Therefore, it is essentially a resource-consuming consumption mode, ignoring resources. Saving, recycling and recycling make great harm to the environment, so destroying the ecological balance is a non-sustainable consumption. Green consumption is the opposite. As an inevitable institutional choice, we should continue to discuss how to do it so that the green consumption system can be fully constructed. From the conceptual basis and developmental sources of green consumption, what are the obstacles to the choice of green consumption? How do consumers abandon old consumption habits and choose a green consumption model? Starting from the current dilemma of consumer behavior choices, we gradually solved the obstacles to the establishment of a green consumption system and finally completed the construction of a new consumption system.

\section{THE THEORETICAL ORIGINS OF GREEN CONSUMPTION CONCEPT}

\section{A. Western Social Economics Theories}

1) Homoeconomicus hypothesis: When domestic scholars are explaining the "homoeconomicus" hypothesis, they consider that it contains three basic propositions. The first is self-interest. That is, pursuing self-interest is the fundamental motivation for people to make economic behaviors. The second is rational behavior. That is, people can always get the most benefit based on market conditions, their own conditions and their own interests. Third, as long as there are reliable legal and institutional guarantees, the behaviors of homoeconomicus to maximize personal interests will unconsciously increase the public interest. [1]

Economic theories reflect that the inevitability of scarcity of resources will certainly lead to the competitions among people, which has excluded market monopoly, provided internal motivation for market competition, achieved the goal of optimizing resource configuration, and faced the "selfinterest" of "homoeconomicus".

Starting from the homoeconomicus hypothesis, the consumer behavior is mainly regulated by material consumption and personal interests.

2) Social man hypothesis: The theoretical basis of the "social man" hypothesis is the interpersonal relationship theory, which was originally from the Hawthorne experiment (1924 - 1932) hosted by G.E. Mayo. Mayo believes that a man is a living "social man" with thoughts, feelings, and personality. A man is a member of the complex society, although materials have an important influence on the generation of their enthusiasm, but the decisive influence factor is the interpersonal relationship.

Starting from the "social man" hypothesis, consumption motivation and behavior are not only affected by material stimuli, but also by subjective norms and values, and perceived behavioral control.

There is a boundary between the homoeconomicus hypothesis and the social man hypothesis. The two hypotheses 
are essentially opposite to each other, but if the unity of "homoeconomicus" and "social man" can be realized, the unity of "altruism" and "egoism" can be realized, and the unity of "economic interests" and "environmental interests" can be realized. In this condition, the concept of green consumption gradually emerged under the integration of such ideas.

\section{B. Externality Theory of Sustainable Development}

The epistemological basis of the externality theory sect is that the fundamental reason why the natural environment is deteriorating and there has appeared unsustainable development phenomenons in human society is that human beings have always regarded natural resources and the natural environment as "public items" that can be obtained infinitely and freely, and at the same time, people always believe that natural resources do not have any value in the economic sense, and in economic life, the natural resources and environmental input and consumption are excluded from the economic accounting system.

According to Pigou's "external costs internalization" theory, the activities of economic entities are regulated by the government by means of taxation, fines, compensation, etc., relying on the power of the government and the sound legal system to achieve rational allocation of natural resources. However, Coase put forward an idea of property management. He believes that the externality problems need to be solved by clearing property rights, reducing transaction costs, and relying on relevant departments to negotiate, that is, externality problems can be solved through self-regulation with the market mechanism without relying on government regulation.

Based on this understanding, the externality theory of sustainable development further explores whether natural resources should be included in the economic accounting system from the perspective of economics. For consumers, the scope of the economic accounting system must include the arrangement and plan of natural resources. Therefore, protecting and saving resources has become an inevitable choice for consumers.

\section{Theory of Ecological Civilization System Construction}

The report of the 18th Session of National Congress first proposed issues related to vigorously promoting the construction of ecological civilization, and called for the formation of spatial patterns, industrial structures, production methods and lifestyles that are conducive to resource conservation and environmental protection. The report of the 19th Session of National Congress also mentioned: We should construct a modern society in which human is in harmony with the nature.

The lifestyle under the construction of ecological civilization should be a way of saving resources and energy, being friendly to the environment, and being green and healthy. A green and healthy lifestyle must meet the following three conditions: first, the materials consumed by consumers in their lives are good or at least harmless to health; second, consumers pay attention to saving resources and energy in their daily work and life; third, the items used by consumers should be environmentally friendly and not pollute the environment.
In order to promote the development of green consumption, build a green, low-carbon, and circularly-developed economic system, the requirements of "green consumption" for consumers have been put forward, namely: advocate the simple and modest, green and low-carbon lifestyle, and oppose extravagance, waste and unreasonable consumption. China's green consumption concept theory has begun to mature.

This theory puts forward requirements for consumers' consumption behaviors. At the same time, green consumption has an important role of promoting the production of green products. The virtuous cycle of green consumption and green production will become the support for China's ecological civilization construction and sustainable development.

\section{CUltural VAluES AND THE "CONSUMERISM" DILEMMA}

\section{A. Deviation of Cultural Values}

The cultural values proposed by Su Song and other scholars refer to the beliefs that most members of society believe in and advocate. Cultural values influence the attitudes and behaviors of members of society by forming the norms.

China's traditional culture emphasizes the harmonious unity between man and nature, advocates the "harmony between man and nature", advocates simplicity, emphasizes that individual interests should obey the collective interests, and people often have collectivist values. Previous studies have also shown that most consumers in China have the attitude and willingness of green consumption. However, consumers' lack of awareness of green consumption behaviors makes their green consumption attitudes and willingness lack a realistic foundation, which will result in the short-term nature of their green consumption behaviors. In other words, most consumers in China have never generated or refused to generate the will to maintain the natural environment through making green consumption behaviors.

In addition, due to the frequent occurrence of problems in products in the market, there may be businesses that use this as a gimmick to promote their general products or even inferior products to obtain huge profits and deceive consumers. Some consumers with green consumption willingness, in the absence of judgment and experience for green products, are concerned that the purchase of false green products may result in the loss of property, body health and personal image, and turn to the purchase of general products to avoid risks. This has ultimately led to a departure between green consumption attitudes, willingness and green consumption behaviors. ${ }^{2]}$

\section{B. The Emergence of "Consumerism"}

Consumerism refers to the value and lifestyle that people consume materials and natural resources unrestrainedly, make high consumption to meet spiritual and material desires, and take consumption as the highest purpose of life and values.

According to the data of the National Bureau of Statistics, the 2017 per capita disposable income of the national residents is 25,974 yuan, increasing $7.3 \%$ over the past year, which is higher than the economic growth rate. The per capita 
disposable income of urban and rural residents has respectively increased by $6.5 \%$ and $7.3 \% .{ }^{[3]}$ However, the increase in green consumption is not entirely proportional to the increase in consumption levels. On the contrary, in the absence of the concept of green consumption, the phenomenon of high consumption and excessive consumption is more obvious.

Since the reform and opening up, the rapid economic development, and the tremendous growth of social productivity and material wealth have laid the foundation for the formation of China's consumer society. In the 30 years before the reform and opening up, within the framework of China's overall social interest structure, people gradually forgot their personal interests. After the reform and opening up, the first and biggest change is the change of social interest relationship, and people's interest consciousness begins to awaken. At the same time, the original overall interest structure collapsed into countless small pieces, resulting in the individualization of social interest units. The whole society presents a phenomenon of being hungry and thirsty for interests. The Chinese people's enthusiasm and ability to pursue material wealth have been unprecedentedly released. ${ }^{[4]}$

The emergence of "consumerism" has become one of the most important factors that hinder people from choosing green consumption. Suppressing the phenomenon of "consumerism" and changing the original consumption patterns and values have become an inevitable choice for the formation of the green consumption concept.

\section{The Negative Impact of the Luxury Consumption Pattern}

Luxury consumption is an extreme expression of excessive pursuit of hedonic consumption. From the perspective of resources, such a consumption pattern has caused huge waste of resources; from the perspective of social psychology, it has also led to the emulation or dissatisfaction of ordinary consumer groups, exacerbating social problems. The issue of luxury consumption has also been extensively explored in the field of social psychology.

The reason why luxury goods become luxuries is not only that they are expensive, but also that these products can bring people the "noble" status symbols. So it is inevitable that people who cannot afford luxury goods will feel "social exclusion". The need for interpersonal belonging is one of the most basic and universal motives of human behaviors, and social exclusion is often a painful and threatening experience. "Jealousy, vanity and eagerness to consume" are normal emotional reactions in people's response to this threatening experience.

For those who produce luxury goods, they don't have to worry about what people who can't afford the goods are thinking, because they are not the sales target group. Therefore, to eliminate the negative impact of luxury consumption, the key is to change the self-awareness and behavior of the ordinary consumer groups. The opposite of social exclusion is social acceptance. In the scenario of "seeing others buy luxury goods", there are two ways to seek acceptance in short terms: one is to simply exclude luxury consumption, which is also not beneficial to the formation of green consumption behavior; the other is "seeking acceptance", that is, relying on presenting the characteristics which are admired by luxury consumer circles to gain recognition, which also runs counter to the concept of rational consumption and green consumption.

\section{SELF-CONSTRUAL THEORY AND RESPONSE TO CONSUMERISM DILEMMA}

Self-construal refers to the belief that people have a relationship with themselves and others, especially the extent to which they are separated and connected with others (Markus and Kitayama, 1991). Self-construal generally falls into two types: dependent self-construal and independent self-construal. Dependent self-construal is means that builds its own attitudes and actions on the basis of other thoughts, emotions, and actions and independent self-construal is a way of establishing personal attitudes and behaviors based on the thoughts, feelings, and behaviors of oneself rather than others. Generally speaking, individuals in the Western cultural context show a strong independent self-construal, which is related to the cultural atmosphere in which Western society encourages individuals to discover and express themselves and is more inclined to emphasize individual independence; and individuals in the context of oriental culture tend to have a strong dependent self-construal, because Eastern culture generally emphasizes the connection and dependence of individuals to social backgrounds.[5]

\section{A. Core Values Guide Consumption Concept}

The eighteenth National Congress of the Communist Party of China clearly put forward the basic national conditions of our country, that is, China is still in and will be in the primary stage of socialism for a long time. The consumption level and consumption level of the developing countries are determined by the national conditions and the level of social development. The correct cultivation of consumption concept needs to be guided by socialist core values.

The authoritative explanation given by the Ministry of Environmental Protection of China on the green of lifestyle in 2015 is "to carry out green living actions and promote the whole people's ways of saving, green, low-carbon, civilized and healthy in clothing, food, housing, travel and tourism. change".[6] According to the theory of self-construal, consumers in China generally belong to the type of "dependent self-construal". Consumers are more willing to accept the guidance and encouragement of social authority to naturally generate the concept of green consumption guided by core values and conduct green consumption. At the same time, the government or other authoritative departments widely popularize knowledge about green consumer products and give consumers the ability to distinguish green consumer products. Therefore, when the concerns of the "green products are difficult to distinguish" are eliminated, the green consumption method will sway the market rapidly.

\section{B. Give Play to the Innovative Role of Consumers}

Consumer innovation refers to the ability of individuals and other individuals to make independent decisions without communication and experience sharing. Consumer innovation is divided into three categories: the first category is inherently 
innovative, that is, the potential psychological characteristics of consumers that like to accept of new products; the second category is innovation in specific areas, that is, consumers' understanding of new products in a specific field and the tendency to adopt; the third category is the actual innovation, that is, the state in which consumers adopt new products earlier than others in the social system. ${ }^{[7]}$ The level of innovation traits of these three types of consumers is gradually increasing, and the formation of green consumption concepts is also increasing. However, regardless of the strength of innovation, as long as there is a greater possibility of green consumption behavior, it should be guided to further develop.

Therefore, in the process of guiding green consumption, government policy formulation and management, green production enterprises, and other relevant social organizations should pay full attention to consumer groups with strong innovations. Such consumer groups often have role models for other consumers and affect the consumption concept of other consumers and drive the green consumer behavior of the overall consumer.

\section{Enhancing the Will to Green Consumption (Green Products of Personal Profit and Public Welfare)}

The consumer's will process is the stage in which after clearing the behavioral goals and preparing to achieve the intended purchase purpose after various psychological activities. That is to say, when consumers form a green willingness to consume, they also need to analyze the various obstacles that need to be overcome to put the behavior into practice. The analysis results ultimately determine the degree to which their willingness transforms into actual behavior. In this process, two important factors are subjective norms and perceived behavioral control. ${ }^{[8]}$

From the consumer's own point of view, the first is that the more subjective normative consciousness of the individual, the more susceptible it is to the outside world, and the more likely it is to be recognized by others. In other words, when green consumption becomes a consumption pattern widely followed by social groups, other individuals will choose green consumption patterns to seek social identity under this influence. The second is that in the consumer's perceived behavior control, if the obstacles to the expected behavior of consumer behavior decrease and the promotion factors increase, they will be more willing to adopt such behavior; on the contrary, even if there is a willingness to consume, it is still difficult to achieve concrete green consumption behavior. That is to say, when consumers purchase products, the comparison of the advantages and disadvantages of green goods and ordinary goods, the use experience, the price and the protection of consumer rights have become factors that promote or hinder consumers from choosing green products.

\section{CONCLUSION}

Therefore, it is necessary to enhance the propaganda of green consumption concepts and increase the awareness of green consumption; at the same time, green product manufacturers should improve the quality of green products and their advantages. In addition, consumers' consumer rights must be improved and protected to make them understand the public interest, personal interests, and consumer rights protection of the green consumption behavior. Meanwhile, it's important to increase the expected promotion factors of consumer behavior so that the will of consumers to green consumption can be enhanced, with a view to promoting the construction of a green consumption system.

\section{REFERENCES}

[1] Zhong Xiangcai. A Comparative Analysis of the Description of "Selfprofit" in Ancient China and the "Economic Man" Hypothesis in the West[J]. Social Sciences,2006(7).

[2] Chen Kai, Guo Fen, Zhao Zhanbo. Analysis of the Mechanism of Psychological Factors in Green Consumer Behavior_-Based on the Research Perspective of Psychological Process of Green Consumer Behavior[J].Enterprise Economy,2013(1).

[3] National Development and Reform Commission: in 2017, the per capita disposable income of the national population was 25974 Yuan. [EB/OL].[2018-3-30].

http://www.dzwww.com/xinwen/guoneixinwen/201803/t20180330_172 08803.htm.

http://www.dzwww.com/xinwen/guoneixinwen/201803/t20180330_172 08803.htm

[4] Cui Haibo. The Rise and Spread of American Consumerism and Its Influence on China College Students' Consumption Values[J].Cutting Edge Education,2007(3).

[5] Wang Lulu. The Influence of Chinese Traditional Cultural Values on Environmental Behaviors-Based on Green Product Buying Behavior of Consumer[J].Journal of Shanghai University of Finance and Economics,2015(2).

[6] Environmental Protection Department, People's Republic of China. Implementation Views on Accelerating the Greening of Life Style[EB/OL].[2015-11-16].

http://www.mep.gov.cn/gkml/hbb/bwj/201511/t20151116_317156.htm.

[7] Quoted from Sheng Guanghua, Gao Jian. Research on the Transformation Mechanism of Lifestyle Greening_From the Perspective of Green Consumption. Journal of Xi'an Jiao Tong University,2016(7).

[8] Same as [2]. 